\title{
Chronic Glycemic Control in Surgical Patients admitted at a Tertiary Care Hospital
}

Hassan Mahmood Tabassum, ${ }^{1}$ Muhammad Haseeb, ${ }^{2}$ Kashif Ali, ${ }^{3}$ Muhammad Muneeb, ${ }^{4}$ Noor Ahmad Niazi ${ }^{1}$

\begin{abstract}
Background: Surgeons are performing millions of operations on diabetic patients daily, and lack of awareness among diabetic patients is leading to complications.

Objective: To determine chronic glycemic control in general surgical patients admitted at a tertiary care hospital.

Methodology: This was a cross-sectional study conducted from June 2018 to January 2019, on fifty-seven consecutive patients, suffering from diabetes and needing surgical intervention in any form were included in this study. Diabetes status in terms of HbA1c, causes of admission to the surgical ward, and intervention done were noted. Data were analyzed by using SPSS 20.

Results: Among these diabetic patients, 46 (80.70\%) were male, and 36 (63.16\%) were known diabetics. HbA1c level was normal in $9(15.79 \%)$ patients, pre-diabetic in $13(22.81 \%)$ and uncontrolled diabetic in $35(61.4 \%)$ patients. Aetiologically diabetic foot was seen in $36(63.16 \%)$ patients, abdominal catastrophe 12 (21.05\%), leg swelling 7 (12.09\%), 5 (8.77\%) scrotal abscess, carbuncles 4 (7.02\%), miscellaneous $5(8.77 \%)$. Incision drainage and closure were done in $10(17.54 \%)$, drainage wound debridement, decompression of compartment syndrome, and constructive procedure in $11(19.3 \%)$, laparotomy $8(8.77 \%)$ and watchful conservation in $4(7.01 \%)$ patients. Two patients were saved from the mortal blow of the diabetic coma. Hypertension and nephropathy were seen in 8 patients each, and 5 patients have Hepatitis $\mathrm{C}$, and 1 patient has ischemic heart disease.

Conclusion: This study showed that many patients did not know their diabetes status, two-third of patients were having uncontrolled diabetes. There is a need for proper assessment and management of diabetic patients by consultants and young doctors in every discipline of medicine, especially surgery.
\end{abstract}

Keywords: Diabetes mellitus, Surgery, Glycemic control.

Article Citation: Tabassum HM, Haseeb M, Ali K, Muneeb M, Niazi NA. Chronic Glycemic Control in Surgical Patients admitted at a Tertiary Care Hospital. JSZMC 2020;11(2):39-42. DOI: https://doi.org/10.47883/jszmc.v11i2.105

\section{Introduction}

Diabetes Mellitus is a chronic metabolic disorder characterized by hyperglycemia resulting from defects in insulin secretion or action or both. It has affected about 26 million people in the United States alone. ${ }^{1}$ Currently, an epidemic of type 2 diabetes is being witnessed throughout the world. It is resulting in an ever-increasing number of diabetic patients with its complications. In Pakistan, the prevalence of type 2 diabetes is estimated to be $11.77 \%$. ${ }^{2}$ The current incidence of insulin-dependent diabetes mellitus varies between $<1 / 100,000$ to $>40 / 100,000$ of the world population. Well-defined stages can characterize symptomatic type 1 diabetes. ${ }^{3} \mathrm{HbA} 1 \mathrm{c}$ is a marker used for the diagnosis and management of diabetes. ${ }^{4}$ Regardless of the type of diabetes, patients with uncontrolled diabetes mellitus exhibit a significant increase in the rate of surgical and systemic complications, higher mortality, and length of stay in the hospital. ${ }^{5}$ The postoperative complications include infections, cardiac events, and acute renal failure. ${ }^{6}$ On the contrary, it is observed that normal glycemic or tight glycemic control has demonstrated increase 90-day mortality in intensive care patients. This finding has dampened the enthusiasm for 'tight glycemic control'. '

Surgery performed electively or in the emergency, causes catabolic stress on the patient and leads to the secretion of counter-regulatory hormones both in normal or diabetic subjects. These hormones increase glycogenolysis, gluconeogenesis, lipolysis, and proteolysis, and insulin resistance. ${ }^{8}$ In addition to other risk factors including the large size of the tumor, smoking, and obesity, diabetes mellitus is an independent risk factor in anastomotic failure. ${ }^{9}$

1. Department of Surgery, Sheikh Zayed Medical College/Hospital, Rahim Yar Khan, University of Health Sciences, Lahore, Pakistan.

2. Ex. House Officer, Sheikh Zayed Medical College/Hospital, Rahim Yar Khan, University of Health Sciences, Lahore, Pakistan.

3. Department of Plastic Surgery, Sheikh Zayed Medical College/Hospital, Rahim Yar Khan, University of Health Sciences, Lahore, Pakistan.

4. RHC, Bangla Manthar, Rahim Yar Khan.

Correspondence: Prof. Dr. Hassan Mahmood Tabassum, Department of Surgery, Sheikh Zayed Medical College/Hospital, Rahim Yar Khan, Pakistan. 
Diabetes mellitus is a risk factor in the revised cardiac risk index of Lee. For elective surgery HBA 1c of less than $69 \mathrm{~mol} / \mathrm{mol}$ is recommended. ${ }^{10}$

Body sugar is assessed and monitored by plasma sugar, plasma ketone bodies, and Glycosylated hemoglobin HbA1C. Urinary sugar control monitoring is usually not practiced nowadays. The DexCom and MiniMed Medtronic systems can monitor short term serum glucose. These systems involve inserting a subcutaneous sensor that measures glucose concentrations in the interstitial fluid for 72 hours. ${ }^{11}$ Glycosylated hemoglobin measurement is a useful index of long-term blood glucose levels monitoring. It reflects glycemic control over 2-3 months. ${ }^{12}$ On the other hand, it is also seen that by adjusting glucose-lowering therapy many patients do not achieve glycemic targets seen in terms of glycosylated hemoglobin level, ${ }^{13}$ literature has reported concerns about using only the glycosylated hemoglobin (HbAlc) level is misleading as it over-diagnose prediabetics. ${ }^{14}$ Correlation of HbAlc levels with glycemic status is as; Normal HbA1c, 4-5.6\%, Pre-diabetic HbA1c, 5.7\%-6.5\%, and Diabetic HbAlc, more than $6.5 \%$. The objective of this study was to determine the chronic glycemic control in the general surgical patients, admitted in surgical ward at the tertiary care hospital.

\section{Methodology}

A descriptive observational study was conducted from June 2018 to January 2019, undertaken at Surgical Unit II, Sheikh Zayed Hospital, Rahim Yar Khan. It was carried out after the approval from the Institutional Ethical Review Board and informed verbal consent was taken from every patient. It included 57 consecutive surgical patients admitted for any surgical reason in the ward. Serum sugar was estimated in all the patients admitted in the ward. Patients with raised serum sugar levels were scrutinized by clinical evaluation and $\mathrm{HbAlc}$. Patients neither having raised serum sugar level nor needing surgical consultation/intervention were excluded from the study. The diabetic patients needing either surgical consultant decision or surgical intervention were included in this study. Age, sex, awareness about diabetes status, surgical conditions needing surgical intervention/decision, management provided to the patient, and associated medical conditions were recorded.

\section{Results}

This study consisted of 57 diabetic patients who underwent surgery. The results are shown in Table I. It included $46(80.7 \%)$ male patients, only 19 $(33.34 \%)$ patients were unaware that they had diabetes, and $19(34.4 \%)$ of these diabetic patients were neither taking any anti-diabetic medicine nor observing anti-diabetic lifestyle. HbA1c level were normal in $9(15.79 \%)$ patients, pre-diabetic in 13 (22.81\%) and uncontrolled diabetic in 35 (61.4\%) patients. Aetiologically, diabetic foot was in 36 (63.16\%) patients, abdominal catastrophe $12(21 \%)$, leg swelling $7(12.09 \%), 5(8.77 \%)$ scrotal abscesses, carbuncles $4(7 \%)$, and miscellaneous 5 $(8.77 \%)$.

Table-I: Demographic, clinical, and HbA1c levels among Patients

\begin{tabular}{|c|c|c|}
\hline Variable & Number & Percentage \\
\hline \multicolumn{3}{|l|}{ Age in years } \\
\hline $20-29$ & 2 & $3.51 \%$ \\
\hline $30-39$ & 4 & $7 \%$ \\
\hline $40-49$ & 11 & $19.3 \%$ \\
\hline $50-59$ & 22 & $38.6 \%$ \\
\hline $60-69$ & 18 & $31.58 \%$ \\
\hline \multicolumn{3}{|l|}{ Sex } \\
\hline Male & 46 & $80.7 \%$ \\
\hline Female & 11 & $19.3 \%$ \\
\hline \multicolumn{3}{|l|}{ Diabetes status awareness } \\
\hline Known diabetic & 36 & $63.16 \%$ \\
\hline $\begin{array}{l}\text { Unknown diabetic, but } \\
\text { proven }\end{array}$ & 19 & $33.33 \%$ \\
\hline $\begin{array}{l}\text { Suspected diabetic, not } \\
\text { proven }\end{array}$ & 02 & $03.51 \%$ \\
\hline \multicolumn{3}{|l|}{ Diabetic treatment taken } \\
\hline Insulin & $27 / 55$ & $49.09 \%$ \\
\hline $\begin{array}{l}\text { Oral hypoglycemic } \\
\text { agents }\end{array}$ & $07 / 55$ & $12.73 \%$ \\
\hline No treatment & $19 / 55$ & $34.54 \%$ \\
\hline \multicolumn{3}{|l|}{ HbA1c level } \\
\hline $4-5.6 \%$ & 09 & $15.79 \%$ \\
\hline $5.7-6.5 \%$ & 13 & $22.81 \%$ \\
\hline$>6.5 \%$ & 35 & $61.40 \%$ \\
\hline \multicolumn{3}{|l|}{ Surgical diseases } \\
\hline Diabetic foot & 36 & $63.16 \%$ \\
\hline Abdominal catastrophe & 12 & $21.05 \%$ \\
\hline Leg swelling & 07 & $12.09 \%$ \\
\hline Scrotal abscess & 05 & $8.77 \%$ \\
\hline Carbuncle back & 04 & $7.02 \%$ \\
\hline Miscellaneous group & 05 & $8.77 \%$ \\
\hline
\end{tabular}

The procedure done was incision drainage and wound closure in 10 (17.54\%), wound debridement, decompression of compartment syndrome, and 
constructive procedure $11(19.30 \%)$, laparotomy 8 $(8.77 \%)$ and watchful conservation in $4(7 \%)$ patients. Two patients were saved from the mortal blow of diabetic coma. Hypertension and nephropathy were seen in 8 patients each. In 5 patients have Hepatitis $\mathrm{C}$, and 1 patient has ischemic heart disease.

Among the patients suffering from abdominal catastrophes diagnosis was; Cholecystitis 2, intestinal obstruction 2, wound failure 1 , mesenteric ischemia 1 , duodenal ulcer perforation 1 , carcinoma of the rectum with liver metastasis 1 , appendix abscess 1, acute appendicitis 1, wanted ileostomy stoma reversal in 1 and liver trauma in 1. The miscellaneous group included bedsore 2 , an abscess on the back of neck 1, cellulitis forearm 1 , and Fournier's' Gangrene in 1. Some of the patients had multiple system involvement. A patient having mesenteric ischemia and another with limb ischemia included in this study neither were clinical diabetic nor on $\mathrm{HbA} 1 \mathrm{c}$ proved them diabetic. Some of the patients needed multiple procedures. Twenty-seven patients underwent amputations. Among these diabetic foot amputations, 6 were Ray's amputations, 2 Forefoot amputations, 13 below-knee amputations, and six above-knee amputations. Management done of patients included in the study is shown in table II.

Table-II: Surgical Procedure carried on Patients

\begin{tabular}{|l|c|c|}
\hline Surgical procedures & Number & Percentage \\
\hline Amputations & 27 & $47.37 \%$ \\
\hline Laparotomy & 08 & $14.03 \%$ \\
\hline Incision drainage & 10 & $17.54 \%$ \\
\hline $\begin{array}{l}\text { Incision drainage /wound } \\
\text { debridement/reconstruction }\end{array}$ & 11 & $19.30 \%$ \\
\hline Delayed wound closure & 05 & $8.77 \%$ \\
\hline Watchful conservation & 04 & $7.01 \%$ \\
\hline Associated conditions & & \\
\hline Hypertension & 08 & $14.03 \%$ \\
\hline Nephropathy & 08 & $14.03 \%$ \\
\hline Hepatitis C & 05 & $8.77 \%$ \\
\hline Encephalopathy & 02 & $3.50 \%$ \\
\hline Ischemic heart disease & 01 & $1.75 \%$ \\
\hline
\end{tabular}

\section{Discussion}

In the current study, 57 patients suffering from diabetes mellitus were included. Among the patients, $36(63.16 \%)$ were knowing diabetes status, while $19(33.34 \%)$ patients were unaware that they were suffering from diabetics. In the current study, $19(34.4 \%)$ of diabetic patients, were neither taking any anti-diabetic medicine nor observing an anti-diabetic lifestyle. Our study verifies the observation of $\mathrm{K}$ Itchlew et al, that there are a significant number of undiagnosed asymptomatic diabetics in the population. ${ }^{15}$

Though retinopathy, nephropathy, diabetic foot, hypertension cardiovascular involvement are common complications of diabetes yet our study verifies that all the organs are affected by diabetes mellitus. The involvement of foot is a common presentation in diabetics, in our study. In the majority of diabetic patients, there is an association of hypertension and nephropathy which correlates well with the study of Akhtar et al, ${ }^{16}$ Hepatitis $\mathrm{C}$ is an additional co-morbidity in our part of the world. Our study endorses the recommendation of Eknithise et al that knowledge, perception, and practice toward self-care among elderly patients suffering from type 2 Diabetes Mellitus were poor. ${ }^{17}$ It is also observed by Kamran et al that due to lack of knowledge, about half of the people with diabetes use herbal medicine. $^{18}$

In modern diabetes management is the focus is to provide holistic and individualized patient care. It is based on structured education, self-management, and safe and effective glucose-lowering therapies. The research studies support concentrating diabetic care on consultants with special interests in diabetes as more innovative and integrated models of care and task-sharing care. These modules include the involvement of the pharmacists in patient care. As more studies are needed to identify the effect of health system arrangements on various outcomes, ${ }^{19}$ the rest of the medical community and population at large must also be educated in the care of diabetes and its complications. Astonishingly in the modern world, Non-insulin-dependent diabetes is being controlled in the severely obese patients by gastric bypass surgery, ${ }^{20}$ but our population is unaware of diabetes.

In our study of 55 proven diabetic patients, only 9 $(15.09 \%)$ diabetic showed normal glycosylated Haemoglobin levels, while the rest 13 (22.81\%) showed either pre-diabetic levels or uncontrolled diabetic levels as seen in $35(61.4 \%)$ patients. It is an indicator that our population has uncontrolled diabetes on a larger scale. Glucose monitoring by urine glucose detection has become out of vogue in 
the recent past. Monitoring of diabetes is recommended by measurement of plasma glucose monitoring, ketone body monitoring in emergency, and $\mathrm{HbAlc}$ level from chronic glycemic control. ${ }^{21} \mathrm{HbA} 1 \mathrm{c}$ is essential for adjusting therapy. The HbAlc derived average glucose study supported that relationship between average glucose in the previous three months, there is, however, substantial individual variability, for $\mathrm{HbA} 1 \mathrm{c}$ values between $6.9 \%$ and $7.1 \%$, the glucose level ranges from $125 \mathrm{mg} / \mathrm{dl}$ and $152 \mathrm{mg} / \mathrm{dl}$ and for $8 \%$ the range from $147 \mathrm{mg} / \mathrm{dl}$ to $217 \mathrm{mg} / \mathrm{dl}$. For this reason, caution should be exercised in estimating average glucose levels for measured $\mathrm{HbA} 1 \mathrm{c} .^{22}$

There is evidence that the prevalence of depression is moderately increased in pre-diabetic patients and undiagnosed diabetic patients, but the ignorance about diabetes is seen in our study. ${ }^{23}$ It needs further evaluation in the Pakistani population. Now it is being appreciated that people with diabetes need a lot of selfmanagement and education (DSME). A wide variety of DSME programmes are being organized because for most people diabetes education is not truly embedded in routine clinical care. In comparison to drugs and devices, DSME lacks investment and funding. Collaboration and leadership are required to overcome these deficiencies. $^{24}$

\section{Conclusion}

A large segment of our patients admitted in the surgical ward did not know that they have diabetes, and two-third was having uncontrolled diabetes. The proper screening and management of diabetic patients by consultants and young doctors in every discipline of medicine especially surgery is the need of time. Every health caregiver and patient must remain conscious of diabetes.

Authors Contribution: HMT: Conception of work and Design of Work. MH: Drafting and Revising. KA: Acquisition \& analysis. MM: Analysis of data and drafting. NAN: Drafting and Revising.

All the authors gave final approval for publication and agreed to be accountable for all aspect of work.

Conflict of Interest: None

Sources of Funding: Self

\section{References}

1. Yang SJ, Lu CC, Kuo SC. Autophagy and its link to type II diabetes mellitus. Biomedicine (Taipei) 2017;7(2):8-15 DOI:10.1051/bmden/2017070201

2. Akhtar A, Ahmad S, Tabassum HM. Diabetic Foot Amputation; frequency of diabetic nephropathy among the patient. Professional Med J 2017;24(2):302-307

3. Meo AS, Zia I, Bukhari AI. The current prevalence of type 2 diabetes mellitus in Pakistan. J Pak Med Assoc 2016 Dec;66(12):1637-1642.

4. Insel RA, Dunne LJ, Atkinson AM. Staging Presymptomatic Type 1 Diabetes: A Scientific Statement of JDRF. Endocrine Society, and the American Diabetes Care 2015 Oct; 38(10):1964-1974

5. Rhea MJ, Molinaro R. Pathology Consultation on HbAlc Methods and Interferences. American Journal of Clinical Pathology 2014;141(1): 5-16

6. Railkundalia DM, Fang HC, Spinazzi FE. Impact of Diabetes Mellitus on Head and Neck Cancer Patients Undergoing Surgery. Head and Neck Surgery 2015 Oct;(6):294-299

7. Krinsley SJ. Glycemic control in the critically ill: What have we learned since NICE-SUGAR? Hospital Practice 2015;43(3):191-197

8. Frier MB, Fisher M. Diabetes Mellitus. Davidson Medicine Colledge NR, Walker BR, Ralston SH, Churchill Living stones, Elsevier 2014;(21):796-835

9. Marta P, Roel H, Steve A et al. Incidence and risk factors for anastomotic failure in 1594 patients treated by Transanal Total Mesorectal Excision, Results From the International TATME Registry. Annals of Surg 2019;269 (4):700-711

10. William SN, Connell CRP, Maccaskie Aw. Perioperative care including the high-risk surgical patients. Bailey \&Love Short Practice of Surgery, 27th edition; 2018 CRC Press (17):254-268

11. Stephen J, Mcphedd IMA, Papadakis. Diabetes Mellitus and hypoglycaemia. Current Medical Diagnosis and Treatment 2016;(27):1203-50

12. Bikramjit P, Raveender N, Sudipta P. The importance of $\mathrm{HbA1c}$ and erythrocyte sedimentation rate a prognostic factor in predicting the outcome of diabetic foot ulcer disease. Inter Jour of Adv Med 2017;4 (1):137-42

13. Zinman B, Wanner C, Lachin MJ, Fitchett D, Bluhmki E, Hantel S et al. Empagliflozin, cardiovascular outcomes, and mortality in Type 2 Diabetes. N Engl J Med 2015;373:21172128

14. Karakurt M, Acar B, Ozeke O. Advantages and pitfalls of the glycosylated Haemoglobin A1c measurement in acute coronary syndrome: Start simple, evolve to more sophisticated. Angiology 2019 Feb;70(2):182-184.

15. Kitchlew R, Chachar AZK, Haider M. Pre-diabetes; prevalence of prediabetes in our local population. Professional Med J 2017;24(12):1860-1866

16. Akhtar A, Ahmad S, Tabassum HM. Diabetic foot amputation; frequencies of diabetic nephropathy among patient. Professional Med J 2017;24(2):302-307

17. Eknithiset R, Samrongthong R, Kumar RJ. Factors associated with knowledge, perception, and practice toward self-care among elderly patients suffering from type 2 Diabetes Mellitus in rural Thailand. Ayub Medical College Abbottabad 2018;30(1):107-110 
18. Kamaran E, Erkin O, Senman S. The use of herbel supplements by individuals with diabetes mellitus. J Pak Med Assoc 2018;68(4):587-594

19. Ong ES, Koh KJJ, Toh Seas. Assessing the influence of health systems on Type 2 Diabetes Mellitus awareness, treatment, adherence, and control: A systematic review. PLoS ONE 2018;13(3): e0195086.

20. Chatterjee S, Davies MJ. Current management of diabetes mellitus and future directions in care. PMJ 2015:130-142

21. Ahmad M, Michael TI. A review of randomized control trial in surgery. Recent Advances Surgery 2017;38:197-206
22. Masharani IU, Papadakis M, Mc Phee S. Diabetes Mellitus \& Hypoglycaemia Current Medical Diagnosis \& Treatment (Lange Mc GRAW Hill education) 2018:12221268

23. Basescu SV, Tataru CT, Kobylinska L. The association between Diabetes mellitus and depression. Jour of Med and life 2016 Apr-Jun;9 (2):120-125

24. Hurley L, Donnell MO, Clare M, Hara, Carey E M, Willaing I. Is diabetes self-management education still the Cinderella of diabetes care? Patient Educ and Counsel 2017;100(10):1957-1960 